Federal Reserve Bank of Minneapolis

Research Department

\title{
Equilibrium Business Cycles With Idle Resources and Variable Capacity Utilization
}

\author{
Thomas F. Cooley, Gary D. Hansen, \\ and Edward C. Prescott*
}

Working Paper 535

September 1994

\begin{abstract}
A real business cycle economy is studied in which some capital is idle each period and the fraction of capital left idle varies in response to technology shocks. Previous equilibrium business cycle models have the characteristic that the entire stock of capital is used for production in each period. Our objective is to determine whether incorporating idle resources, something regularly observed in actual economies, significantly affects the cyclical properties of the model and hence changes our views about the importance of technology shocks for aggregate fluctuations. In our analysis we do not assume an aggregate production function, but instead model production as taking place at individual plants that are subject to idiosyncratic technology shocks. Each period the plant manager must choose whether to operate the plant or to let the plant remain idle. We find that the cyclical properties of this model are surprisingly similar to those of a standard real business cycles economy. One difference is that the model displays variation in factor shares while the standard model does not.
\end{abstract}

* Cooley, University of Rochester; Hansen, University of California, Los Angeles; and Prescott, University of Minnesota and Federal Reserve Bank of Minneapolis. The authors acknowledge support from the National Science Foundation. The views expressed herein are those of the authors and not necessarily those of the Federal Reserve Bank of Minneapolis or the Federal Reserve System. 


\section{Introduction}

One characteristic of existing real business cycle models is that the entire stock of capital is used for production in each period. However, even casual observation suggests that this is certainly not the casc in the actual economy. One commonly observes idle plants, vacant office buildings and unused equipment. In this paper we construct a real business cycle economy in which some capital is idle each period and the fraction of capital left idle varies in response to technology shocks. Our objective is to determine whether incorporating this feature significantly affects the cyclical properties of the model and hence changes our views about the importance of technology shocks for observed aggregate fluctuations. We find that, although the technology employed in this economy is quite different from ones employed in standard real business cycle models, the conclusions are affected surprisingly little. Incorporating variable capacity utilization does, however, lead to variation in factor shares which are constant in standard real business cycle economies.

We construct a model economy that is similar to a standard equilibrium business cycle models in many respects, including consistency with the long run growth facts, but in which production takes place at individual plants that differ according to an idiosyncratic technology shock. To operate a plant, a fixed number of workers is required and the marginal product of additional workers beyond this number is zero. A particular plant is operated if, given its realized technology shock, it is able to produce enough output to cover its labor costs. Thus, in equilibrium, some plants will operate and others will not. We study the properties of the aggregate fluctuations exhibited by this model economy and compare them with the cyclical properties of a standard real business cycle model and with U.S. data.

We are not the first to study the role of variable capacity utilization in business cycle models. Greenwood, Hercowitz and Huffman (1988), and Greenwood, Hercowitz and Krusell (1992) describe model environments where the intensity with which the capital stock is used may vary in response to shocks 
to the economy. Kydland and Prescott (1991) and Bils and Cho (1993) allow the workweek of capital to respond to aggregate shocks. We take a different approach from these studies in that we allow capital utilization to vary along the "extensive margin." That is, in our model, it is not the intensity or the period of time with which a unit of capital is utilized that is varied (the "intensive margin"), but instead it is the fraction of the capital stock used for production that varies (the extensive margin). A unit of capital is either used in production for a given length of time or it is left idle. ${ }^{2}$

Although the implications of adjusting capital utilization along the extensive margin have not been studied in an equilibrium business cycle context, it is well known that the manner in which the production level is changed can have important implications for business cycles. In the labor market, for example, over half of the variance in aggregate hours worked is attributable to the variance in the number employed and only about 20 percent is unambiguously due to the variance in hours per employed worker. Hence, the majority of the variability in the labor input is due to changes along the extensive margin. Hansen (1985) found that incorporating this feature in a real business cycle model changed the cyclical properties of the economy in important ways relative to an economy in which labor is adjusted only along the intensive margin (hours per worker).

A recent paper by Bresnahan and Ramey (1992) provides some micro evidence that adjusting capital utilization along the extensive margin may be quantitatively important. They study weekly data from 1972 to 1983 for 50 automotive plants and provide statistics on how frequently the automobile industry uses various margins to adjust output. The output produced by a plant is assumed to be proportional to the length of a shift (regular plus overtime hours) multiplied by the number of shifts and the line speed. Regular hours in the automotive industry are usually varied by temporarily shutting a plant

2 Although the economy studied in this paper does not exhibit fluctuations in the work week of capital, we have experimented with a variation of the model in which an overtime shift is introduced as in Hansen and Sargent (1988). In such a model, some capital is used only during the straight time shift, some is used during the straight time and overtime shift, and the remaining capital is idle for the entire period. We found that adding this feature did not affect our findings very much so, in order to simplify our presentation, we chose to ignore the intensive margin in this paper. 
down. They decompose the variance of plant output to determine the importance of these margins. Plant shutdowns and the use of overtime hours (changes in the work week) are by far the most common margins used, yet shutdowns account for 65 percent of the output variance while overtime accounts for only 4 percent. In addition, changes in the number of shifts accounts for 23 percent of the output variability in Bresnahan and Ramey's sample. This evidence suggests that the decision to operate or not operate a plant is an important margin to consider given that it accounts for much of variability in output at the micro level, at least in the automotive industry. Determining whether this has important implications for fluctuations at the aggregate level is the purpose of the exercise conducted here.

We expect that the theoretical framework developed in this paper may be useful in the future for addressing other issues for which heterogeneous production units are important. Since we model production at the plant level, rather than assuming an aggregate production function, this framework can be used to study the effects of policies and regulations that restrict production at the plant level. For example, this framework might be useful for studying the effects of restrictions on the ability of companies to close or temporarily shut down plants.

The remainder of the paper is organized as follows. The model economy is described in the next scction and the procedure used to solve for an equilibrium is explained in section 3 . The fourth section describes the model calibration and the fifth section presents our results and conclusions.

\section{Model Economy}

The economy is populated by a continuum of infinitely lived households and the total measure of these households is one. Households are ex ante identical and seek to maximize expected discounted lifetime utility,

$$
E \sum_{t=0}^{\infty} \beta^{t}\left(\log c_{t}+\gamma \log l_{t}\right)
$$


where $c_{t}$ and $l_{t}$ are consumption and leisure in period $t$, respectively. Households are assumed to be endowed with one unit of time that can be allocated to either work, $h_{t}$, or lejsure, so $l_{t}=1-h_{t}$. Following Rogerson (1988) and Hansen (1985), labor is assumed to be indivisible; in a given period households can work either a shift of length $h_{0}$ or not at all, where $h_{0}$ is an exogenous parameter.

Households also accumulate productive capital which they rent to individual plants to be used in production. Letting $K_{t}$ be the capital owned by a representative household, the capital held at the beginning of the subsequent period is,

$$
K_{t+1}=(1-\delta) K_{t}+x_{t}, \quad 0 \leq \delta \leq 1,
$$

where $x_{t}$ is investment undertaken in period $t^{3}$

Production is carried out at a continuum of autonomous plants with measure $m_{\mathrm{t}}$, each indexed by a productivity parameter, $s_{t}$. A plant consists of a location plus physical capital. In addition, $\eta$ workers are required to operate the plant and the marginal productivity of additional workers beyond $\eta$ is zero.

The output produced by a plant with $k_{t}$ units of capital and $q_{t}$ workers is given by,

$$
y_{t}=\left\{\begin{array}{cl}
\left(s_{t}+z_{t}\right) k_{t}^{\theta} h\left(s_{t}\right) & \text { if } q_{t} \geq \eta \\
0 & \text { otherwise }
\end{array}\right.
$$

where $z_{t}$ is an economy wide technology shock, $h\left(s_{t}\right)$ is the number of hours the plant is opcrated and $\theta$ is a parameter between 0 and 1 . The plant specific shock, $s_{t}$, is independent and identically distributed across time and across locations. In particular, we assume that $s_{t}$ is uniformly distributed on the interval $[-\sigma, \sigma]$. The economy wide technology shock evolves according to the law of motion,

$$
\log z_{t+1}=\rho \log z_{t}+\varepsilon_{t+1}
$$

where the random variable $\varepsilon_{t+I}$ is distributed i.i.d. with mean zero and variance $\sigma_{s}^{2}$. The parameter $\rho$ is assumed to be less than or equal to one.

\footnotetext{
${ }^{3}$ Later we use $K$ to denote the aggregate (per capita) stock of capital. This is done to save on notation; given that all households are identical, each household's capital holdings are equal to the per capita stock in equilibrium.
} 
Plants are established by renting capital and placing it in an available location. If there is measure $L_{t}$ locations at the beginning of period $t$, the measure of plants must satisfy the following constraint:

$$
m_{t} \leq L_{t}
$$

Locations are created by incurring a one-time fixed cost of $\phi$ units of output. Once this investment has been made, production can take place at the location in any subsequent period as long as capital is placed there; locations do not disappear or depreciate. In addition, although a location is available for production one period after the investment $\phi$ is made, the decision to create a location must be made $T$ periods prior.

This assumption is made so that the number of locations can not be varied in the "short run" in response to realizations of the shock $z_{t}$, but can be in the "Iong run."

It should be noted that locations are a form of capital in this economy. Locations differ from $K_{t}$ in that it takes $T$ periods to build a unit of $L_{t}$ and only one period to build a unit of $K_{t}$. In addition, $K_{t}$ depreciates while $L_{t}$ does not. Households, as the owners of $L_{t}$, collect any rents that accrue to this factor of production. The rental rate of a location will depend on the value of the parameter $\phi$ and the equilibrium interest rate.

In this paper, we consider two values for the parameter $\phi$. In the first case, $\phi$ is equal to zero, and hence $L_{t}$ is as large as it needs to be so that (5) is never binding. We refer to this as the "variable plants" case. In the second case, $\phi$ is large enough so that (5) is always binding in equilibrium. That is, capital is assigned to all locations with probability one. Also, we assume that $T$ is large enough so that $L_{\mathrm{r}}$ does not vary in response to realizations of the aggregate technology shock. Thus, since $m_{t}$ is equal to a constant in this case, we refer to this as the "fixed plants" case. ${ }^{4}$

At the beginning of a period $t$, the aggregate technology shock $z_{t}$ is observed. At this point the rental market for capital is held in which firms with available locations rent capital from the households

\footnotetext{
4 Intermediate cases in which (5) is sometimes binding and sometimes not may also be interesting, but would have to be studied using computational methods different from the ones employed in this paper.
} 
and establish plants. Hence, the measure of plants, $m_{t}$, is determined subject to constraint (5). At the time a plant is established, the value of $s_{i}$ that will ultimately characterize the plant is unknown. Since all locations appear identical at this stage and $\theta<1$ (in equation 3), all plants will be assigned the same amount of capital. After the idiosyncratic shock $s_{t}$ is observed, the decision is made to operate or not operate the plant. That is, $h\left(s_{t}\right)$ is chosen, where $h\left(s_{t}\right)$ can be either zero or $h_{0}$ hours. This determines the fraction of plants operated during the period, which we denote by $n_{t}$. Hence, the choice of $m_{t}$ determines the amount of capital assigned to each worker and the choice of $n_{t}$ determines the fraction of capital utilized.

\section{Capacity and Capacity Utilization}

We now describe in more detail the determination of the measure of plants, $m_{i}$; the capital assigned to a plant, $k_{i}$; and the fraction of plants that operate, $n_{t}$. Consider first the problem faced by a plant manager after $s_{t}$ has been observed and $m_{t}$ and $k_{t}$ have already been determined. If the hourly wage rate is $w_{t}=w\left(z_{t}, K_{t}\right)$, where $K_{t}$ is the aggregate stock of capital, it will cost $w_{t} h_{0} \eta$ to operate the plant. It is profitable to operate the plant only if the output produced by the plant exceeds this cost. Hence, only plants with sufficiently large realized values of $s_{t}$, those with $\left(s_{t}+z_{t}\right) k_{t}^{\theta} h_{0} \geq w_{t} h_{0} \eta$, will be operated. Thus, there will exist some threshold value of $s$, call it $s\left(z_{t}, K_{t}\right)$, such that $h\left(s_{t}\right)$ equals $h_{0}$ when $s_{t}>s\left(z_{t}, K_{t}\right)$ and equals 0 otherwise. In equilibrium all plants will have the same amount of capital, hence $k_{\mathrm{t}}=K / m_{t}$. This implies that the equilibrium value for $s\left(z_{t} K_{t}\right)$ is given by the solution to the following equation:

$$
\left[s\left(z_{t}, K_{t}\right)+z_{t}\left[\frac{K_{t}}{m_{t}}\right]^{\theta}=w_{t} \eta\right.
$$


Since $s_{t}$ is uniformly distributed, the fraction of plants that operate, $n_{t}$, is given by,

$$
n_{t}=\frac{\sigma-s\left(z_{t}, K_{t}\right)}{2 \sigma}
$$

Combining equations (6) and (7) by eliminating $s\left(z_{t} K_{t}\right)$, we obtain the following equation determining the equilibrium value of $n_{t}$ given $m_{t}$ and $w_{t}$ :

$$
\left[z_{t}+\sigma-2 \sigma n_{t}\right]\left[\frac{K_{t}}{m_{t}}\right]^{\theta}=w\left(z_{t} K_{t}\right) \eta
$$

Next, we consider the problem of a location owner establishing a plant before $s_{t}$ has been realized. The problem is to choose $k_{t}$ to maximize expected profit given $z_{t} w_{t}$ and $r_{t}$, where $r_{t}=r\left(z_{t} K_{t}\right)$ is the rental rate of capital. Expected profit is given by the following expression:

$$
\begin{aligned}
& E\left[\left(s_{t}+z_{t}\right) k_{t}^{\theta} h\left(s_{t}\right)-w_{t} \eta h\left(s_{t}\right) \mid z_{t}, K_{t}\right]-r_{t} k_{t} \\
& \quad=\int_{s\left(z_{t}, K_{t}\right)}^{\sigma}\left(\left(z_{t}+s\right) k_{t}^{\theta}-w_{t} \eta\right) \frac{h_{0}}{2 \sigma} d s-r_{t} k_{t} \\
& \quad=\left(z_{t}+\sigma-\sigma n_{t}\right) n_{t} k_{t}^{\theta} h_{0}-w_{t} \eta h_{0} n_{t}-r_{t} k_{t},
\end{aligned}
$$

where the last equality is obtained by using equation (7) to eliminate $s\left(z_{t}, K_{t}\right)$. Combining the first order condition for maximizing (9) with respect to $k_{t}$ with the fact that in equilibrium $k_{t}=K_{t} / m_{t}$, we obtain the following equilibrium condition for the capital rental market:

$$
\theta\left(z_{t}+\sigma-\sigma n_{t}\right) n_{t}\left[\frac{K_{t}}{m_{t}}\right]^{\theta-1} h_{0}=r\left(z_{t}, K_{t}\right)
$$

The analysis so far applies equally to the "variable plants" and "fixed plant" economies. However, the determination of the measure of plants, $m_{t}$, depends on whether constraint (5) is binding or not. We consider each case in turn. In the variable plants case, in which $\phi=0$, equation (5) is never binding so $m_{t}$ is free to respond to changes in $z$ and $K$. In particular, entry will occur until expected profits (equation (9)) 
are equal to zero. Using equations $(9)$ and $(10)$, this implies that $m_{t}$ will satisfy the following equation:

$$
(1-\theta)\left(z_{t}+\sigma-\sigma n_{t}\right)\left[\frac{K_{t}}{m_{t}}\right]^{\theta}=w\left(z_{t}, K_{t}\right) \eta
$$

In the fixed plants case, the fact that the decision to create a location must be made many periods in advance ( $T$ is large) implies that only unconditional expected profits matter when deciding whether to create a new location. The fact that $\phi$ is large implies that constraint (5) will always bind in equilibrium. Thus, we use the steady state of the certainty version of the model (obtained by setting $z_{t}$ equal to its unconditional mean of 1) to determine the measure of plants. In particular, the number of locations is determined by setting the steady state present value of future profits equal to the fixed cost, $\phi$. Combining steady state versions of equations (8), (9) and (10), this implies the following formula for determining $m_{t}=\bar{m}$, where a "bar" denotes a steady state value:

$$
((1+\theta) \sigma \bar{n}-\theta(1+\sigma))\left[\frac{\bar{K}}{\bar{m}}\right]^{\theta} h_{0} \bar{n}=\phi(r(1, \bar{K})-\delta)
$$

The left side of this equation is steady state profit per period and the right side is $\phi$ multiplied by the steady state interest rate.

Given the wage and rental rate, equations (8) and (11) together determine the equilibrium values of $n_{t}$ and $m_{t}$. Equation (11A) applies in the variable plants $(\phi=0)$ case and (11B) in the fixed plants ( $\phi$ large) case. In the second case, realized profits are positive and are paid as dividends to the owners of the locations. Households, being identical in preferences and endowments, are assumed to own equal shares in all locations. We now proceed to describe the dynamic optimization problem solved by households.

\section{Household's Problem}

Since labor is indivisible in this economy, we follow Rogerson (1988) and Hansen (1985) by allowing agents to trade employment lotteries. Given a wage rate, $w_{t}$, households choose a probability of 
working $h_{0}$ hours, denoted $\pi_{t}$, in order to maximize expected utility:

$$
\pi_{i}\left(\log c_{1 t}+\gamma \log \left(1-h_{0}\right)\right)+\left(1-\pi_{t}\right)\left(\log c_{2 t}+\gamma \log 1\right)
$$

We assume that households are paid $w_{t}$ per hour when they work (which happens with probability $\pi_{t}$ ) and that they have access to a market for unemployment insurance. Since preferences are additively separable in consumption and leisure, households will insure themselves so that their consumption levels are independent of whether or not they work. Given this, the household's optimization can be written as follows:

$$
\begin{gathered}
\operatorname{Max} E \sum_{t=0}^{\infty} \beta^{t}\left(\log c_{t}+\gamma \log \left(1-h_{0}\right) \pi_{t}\right) \\
\text { subject to (2), (4) and } \\
c_{t}+x_{t} \leq w_{t} \pi_{t} h_{0}+r_{t} K_{t}+D_{t}
\end{gathered}
$$

where $D_{t}$ is the dividend paid to the household as an owner of the plant locations. Given that there is a continuum of plants and households are risk averse and ex ante identical, they will diversify their portfolios in such a way that realized dividends are the same for all households. In particular, $D_{t}$ will be equal to the expected profit given in equation (9). Therefore, in equilibrium, $D_{t}$ will equal zero in the variable plants case and will be positive in the fixed plants case. In addition, since there are $m_{t}$ plants, a fraction $n_{\mathrm{t}}$ of these are operated, and $\eta$ workers are required to operate a plant, equilibrium in the labor market requires that $\pi_{t}=\eta m_{\mathrm{s}} n_{\mathrm{s}}$

\section{Computing Equilibrium Allocations}

Since there are no externalities or other distortions in these economies, the equilibrium allocations are Pareto Optimal. Hence, we compute competitive equilibrium allocations by solving the problem of maximizing the welfare of a representative agent subject to an aggregate resource constraint and the law of motion for the stock of capital. This problem can not be solved analytically, so numerical methods are employed. These methods are described in detail in Hansen and Prescott (forthcoming). In this section we 
describe how aggregate resource constraints are derived for the variable plants economy and the fixed plants economy. In addition we derive standard aggregate production functions for these economies. Our procedures do not require production functions for computing equilibrium allocations, but they are useful for understanding how these economies differ from a standard real business cycle economy.

To derive the aggregate resource constraint, we obtain an aggregate production relationship for our economy as follows: given that the density of plants of type $s$ is $\frac{m_{t}}{2 \sigma}$, the total output produced by all plants of type $s$ is,

$$
y\left(s_{t}\right)=\frac{s_{t}+z_{t}}{2 \sigma} K_{t}^{\theta} m_{t}^{1-\theta} h\left(s_{t}\right)
$$

Integrating over all plant types, and using equation (7) to eliminate $s\left(z_{t} K_{t}\right)$, aggregate output $\left(Y_{t}\right)$ turns out to be,

$$
\begin{aligned}
Y_{t} & =\frac{K_{t}^{\theta} m_{t}^{1-\theta} h_{0}}{2 \sigma} \int_{s\left(z_{t}, K_{t}\right)}^{\sigma}\left(s+z_{t}\right) d s \\
& =K_{t}^{\theta} m_{t}^{1-\theta} h_{0}\left[\left(\sigma+z_{t}\right) n_{t}-\sigma n_{t}^{2}\right] .
\end{aligned}
$$

Hence, one way to write the aggregate resource constraint for the economy is $c_{t}+x_{t} \leq Y_{t}$, where $Y_{t}$ is given by equation (14).

Equation (14) highlights the two margins that can be used to adjust the aggregate level of output in the short nun. The choice of $m_{t}$ determines the amount of capital assigned to a plant, and hence the amount of capital per worker. The choice of $n_{t}$, the fraction of plants operated, determines the fraction of the capital stock that is utilized during the period. However, equation (14) is not a production function in the usual sense in that it is not a mapping between inputs and outputs. Equation (14) expresses the maximum output that can be produced as a function of $m_{t}$ and $n_{t}$ rather than hours worked, which is $m_{t} n_{t} h_{0} \eta$. A production function, $\mathrm{F}\left(z_{b} K_{b} H_{t}\right)$, where $H_{t}$ is aggregate hours worked, can be derived from equation (14) as 
follows: ${ }^{5}$

$$
\begin{gathered}
\mathbf{F}\left(z_{t}, K_{t}, H_{t}\right) \equiv \operatorname{Max}_{m_{t}, n_{t}}\left\{K_{t}^{\theta} m_{t}^{1-\theta} h_{0}\left[\left(\sigma+z_{t}\right) n_{t}-\sigma n_{t}^{2}\right]\right\} \\
\text { subject to } H_{t}=h_{0} m_{t} n_{t} \eta
\end{gathered}
$$

We will use this to derive aggregate production functions for the artificial economies later in this section.

The social planner's dynamic programming problem when $\phi=0$, the variable plants case, is as follows (primes denote next period values):

$$
v(z, K)=\operatorname{Max}_{c, x, m, n}\left\{\log c+\gamma \eta \log \left(1-h_{0}\right) n m+\beta E v\left(z^{\prime}, K^{\prime}\right)\right\}
$$

sub ject to

$$
\begin{aligned}
& c+x=K^{\theta} m^{1-\theta} h_{0}\left[(\sigma+z) n-\sigma n^{2}\right] \\
& \log z^{\prime}=\rho \log z+\varepsilon^{\prime}, \quad \varepsilon \sim N\left(0, \sigma_{\varepsilon}^{2}\right) \\
& K^{\prime}=(1-\delta) K+x
\end{aligned}
$$

The planning problem for the fixed plants case is identical to this except that $m$ is no longer a choice variable. Instead, $m=\bar{m}$, where $\bar{m}$ is the solution to the following equation,

$$
((1+\theta) \sigma \bar{n}-\theta(1+\sigma))\left[\frac{\bar{K}}{\bar{m}}\right]^{\theta} h_{0} \bar{n}=\phi\left(\frac{1}{\beta}-1\right) .
$$

In this equation, $\bar{K}$ and $\bar{n}$ are the steady state values obtained from the certainty version of (16) when $m$ is set equal to $\bar{m}$. Equation (17) is obtained from equation (l1B) and the fact that the steady state interest rate is equal to $1 / \beta-1$.

Although we use (16) to obtain equilibrium decision rules for our economy, some intuition can be obtained from studying the production functions for the three artificial economies we will consider in

\footnotetext{
S Note that in this economy the inputs into the production function are aggregate hours (or, equivalently, the number of individuals working $h_{0}$ hours) and aggregate capital. In addition, if we were to incorporate an overtime shift of length $h_{1}$ in this model, as in Yansen and Sargent (1988), the inputs into the production process would no longer only be aggregate hours and capital. Instead, we would have to treat as separate inputs the number of houscholds working $h_{0}$ hours and the number of houscholds working $h_{0}+h_{1}$ hours.
} 
section 5 . The following aggregate production functions are obtained using equation (15):

$$
\begin{array}{ll}
\mathrm{F}\left(z_{t}, K_{t}, H_{t}\right)=z_{t} K_{t}^{\theta} H_{t}^{1-\theta} \eta^{\theta-1} h_{0}^{\theta} & \text { Case I } \\
\mathrm{F}\left(z_{t}, K_{t}, H_{t}\right)=\mathrm{g}\left(z_{t}\right) K_{t}^{\theta} H_{t}^{1-\theta} & \text { Case II } \\
\text { where } \mathrm{g}\left(z_{t}\right)=\left(\frac{\sigma+z_{t}}{1+\theta}\right)^{1+\theta}\left(\frac{\theta h_{0}}{\sigma}\right)^{\theta} \eta^{\theta-1} & \\
\mathrm{~F}\left(z_{t}, K_{t}, H_{t} ; \bar{m}\right)=K_{t}^{\theta} \frac{H_{t}}{\overline{\eta \bar{m}}^{\theta}}\left[z_{t}+\sigma\left(1-\frac{H_{t}}{\bar{m} \eta h_{0}}\right)\right] & \text { Case III }
\end{array}
$$

Case $\mathrm{I}$ is a special case of the variable plants economy in which $\sigma$ is set equal to zero. In this case the idiosyncratic technology shock, $s_{t}$, equals zero at all locations, so all plants are identical. It turns out that the aggregate production function is Cobb-Douglas in this case, so this economy is the same as a standard real business cycle model. ${ }^{6}$ The second case, Case II, is the general version of the variable plants economy. The production function in this case is also Cobb-Douglas with the difference that the technology parameter multiplying $K_{t}^{\theta} H_{t}^{1-\theta}$ is a nonlinear function of $z_{t}$. The production function for the fixed plants economy (Case III) is, however, quite different from the other two. First, it is not CobbDouglas. Second, we have included $\bar{m}$ in the list of inputs, even though it is equal to a constant. The reason for this is that locations in this economy (the measure of which is equal to $\bar{m}$ ) earn positive rents. Hence they must be treated as another form of capital. Although the Case III production function is not Cobb-Douglas, it still has constant returns to scale in $K_{t}, H_{t}$ and $\overline{\boldsymbol{m}}$.

We end this section by noting that there is more than one way to decentralize the solution to problem (16). In the previous section we described an economy in which each plant is an autonomous profit center. This is not the only interpretation consistent with (16). For example, the competitive equilibrium allocation for an economy with a single firm that manages all of the plants with access to the

\footnotetext{
${ }^{6}$ In particular, it is the "indivisible labor" model of Hansen (1985).
} 
technology described by (15) is equivalent to that obtained in an economy with a continuum of autonomous plants. To see this in the variable plants case, note that the single firm's profit is equal to $Y_{t}-w_{t} h_{0} n_{t} m_{t} \eta$ $r_{t} K_{t}$. The first order conditions associated with maximizing this with respect to $n_{\mathrm{b}} K_{\mathrm{b}}$ and $m_{\mathrm{s}}$ yield equations (8), (10) and (11A), respectively. These are the equations that characterize an equilibrium for the original economy. In general, since the aggregate technologies for the economies studied in this paper have constant retums to scale, the number of firms is irrelevant.

\section{Calibration}

In this paper we study three calibrated versions of the model. All three economies have in common that they are restricted so that their nonstochastic steady state is consistent with a list of standard growth facts, features of actual time series that have exhibited little secular change. ${ }^{7}$ These include the fact that in U.S. post Korean war data the average quarterly capital-output ratio is equal to 13.28 , investment as a share of output is .25 , the share of total income that is paid to capital is .4 , and the average fraction of total substitutable time that households spend working in the market is $.31 .^{8}$

The three cases we consider (see equation 18) include two versions of the variable plants economy and one version of the fixed plants economy. In the first case (variable plants with $\sigma=0$ ), which is equivalent to a standard real business cycle model with indivisible labor, $n_{t}$ is equal to one for all $t$ and $m_{t}$ is the only way in which output is varied in the short run. The second case is the variable plants economy with $\sigma$ chosen so that the average rate of capacity utilization is equal to .82 , as measured by the Federal Reserve Board of Govemors (see Raddock (1990)). Here, both the $n_{t}$ and $m_{t}$ margins are used. The final

\footnotetext{
7 This calibration strategy, which is often employed in the real business cycle literature, is described in detail in Cooley and Prescott (forthcoming).

- These facts were obtained by defining capital to be the sum of business equipment and structures, consumer durables, inventories, land and government capital. Output is U.S. Gross National Product plus imputed income from consumer durables and government capital. Investment is gross private domestic investment, purchases of consumer durables, government investment, and net exports. For further details and data sources, see Cooley and Prescott (forthcoming).
} 
case (Case III) is the fixed plants model where $\sigma$ is calibrated using the same criteria as in the second case and the fixed cost $\phi$ is chosen so that $\phi \bar{m} / \bar{Y}$ is equal to the average land-output ratio in the U.S. economy. Of course, in this case output can be varied in the short run only the by adjusting $n_{t}$.

The calibration of the first two cases are identical except for the value of $\sigma$. For these cases, capital's share is equal to $\theta$, so we set this parameter equal to .4. Steady state investment is $\delta \bar{K}$, hence, the depreciation rate is found by dividing the investment-output ratio by the capital-output ratio. This implies a value of .019 for $\delta$. Next, given these parameters, we use the fact that the steady state capitaloutput ratio is $\frac{\theta}{1 / \beta-1+\delta}$ to set $\beta$ equal to .989 . Finally, the parameter $\gamma$ was chosen so that average hours, which are equal to $h_{0} m_{t} n_{t} \eta$, are .31 in the steady state. Thus, we have restricted these economies to match the four growth facts by assigning appropriate values to four of the parameters, $\theta, \delta, \beta$, and $\gamma$.

An important consideration motivating our choice of values for $\eta$ and $h_{0}$ is that only the value of the product, $\gamma \log \left(I-h_{0}\right) \eta$, in problem (16) matters for the steady state growth facts or the cyclical properties of the economy. ${ }^{9}$ As long as $\gamma$ is set so that the average time spent working is .31 , the values assigned to $\eta$ and $h_{0}$ don't matter. Hence, the parameter $\eta$, which is the number of workers needed to operate a plant, is arbitrarily set equal to 1 . A value of .38 was chosen for $h_{0}$ by assuming that a weekly shift is 40 hours and that there are 105 hours during a week that are not unavoidably allocated to sleep or other personal care.

As explained above, the average rate of capacity utilization is used in the second two economies to assign a value to the parameter $\sigma$. We define capacity to be the level of output attained if all plants are operated $\left(n_{t}=1\right)$. This, along with equation (14), implies that the steady state rate of capacity utilization

9 The parameter $h_{0}$ also appears in the resource constraint in (16). Hence the value of this parameter does affect the steady state level of output and capital stock. However, it does not affect either the ratios pinned down by the growth facts or the cyclical properties of the economies. 
(output divided by capacity) is equal to $(1+\sigma) \bar{n}-\sigma \bar{n}^{2}$ in our model. We chose $\sigma$ so that this is equal to .82 .

In the third economy, which is the only case in which the parameter $\phi$ is not zero, we are effectively introducing a second form of capital, locations. The stock of this form of capital is equal to $\phi m_{t}$. In the exercise conducted here, we equate this stock of capital with the stock of land. The steady state capital output ratio is now given by $(\bar{K}+\phi \bar{m}) / \bar{Y}$, and it this ratio that we set equal to 13.28 . The quarterly value of $\bar{K} / \bar{Y}$, which we interpret to include all capital except land, is equal to 10.24 . This additional fact enables us to assign a value to the parameter $\phi$, but also changes the values of $\delta$ (since it is equal to the average investment-capital ratio) and $\theta$. All other parameter values are left unaffected.

The remaining parameters are those describing the stochastic process for $z_{i}: \rho$ and $\sigma_{s}$. These parameters are set so that the model exhibits Solow residuals that have statistical properties identical to the Solow residuals computed from actual data. The Solow residual is defined as follows:

$$
\text { Solow Residual } \equiv \Delta \log Y_{t}-\theta \Delta \log K_{t}-(1-\theta) \Delta \log H_{t},
$$

where $H_{t}$ is hours worked in period $t$. In the first economy, the one with a Cobb-Douglas technology, the Solow residual is equal to $\Delta \log z_{t}$. This, however, does not hold for the other two economies. Examination of the variance and autocorrclations of the Solow residual series lead us to set $\rho$ equal to .95 and $\sigma_{\varepsilon}$ equal to .007 for the first economy. For the second two economies, we search over values of $\sigma_{\varepsilon}$ to find the one such that the standard deviation of the Solow residual series computed from a long simulation of the model is equal to the standard deviation of the Solow residual series computed from U.S. data. ${ }^{10}$ This lead to a different values for $\sigma_{\varepsilon}$ for each of the three economies.

\footnotetext{
${ }^{10}$ We did not need to adjust the autoregressive parameter, $\rho$, since the autocorrelation properties of the Solow residuals are esscntially the same in all three economies.
} 
The following table gives the parameter values assigned in each of the three economies as well as the linear decision rules associated with the social planning problem (15). These decision rules are used to produce the simulation results described in the next section.

Table 1 - Parameter Values and Decision Rules

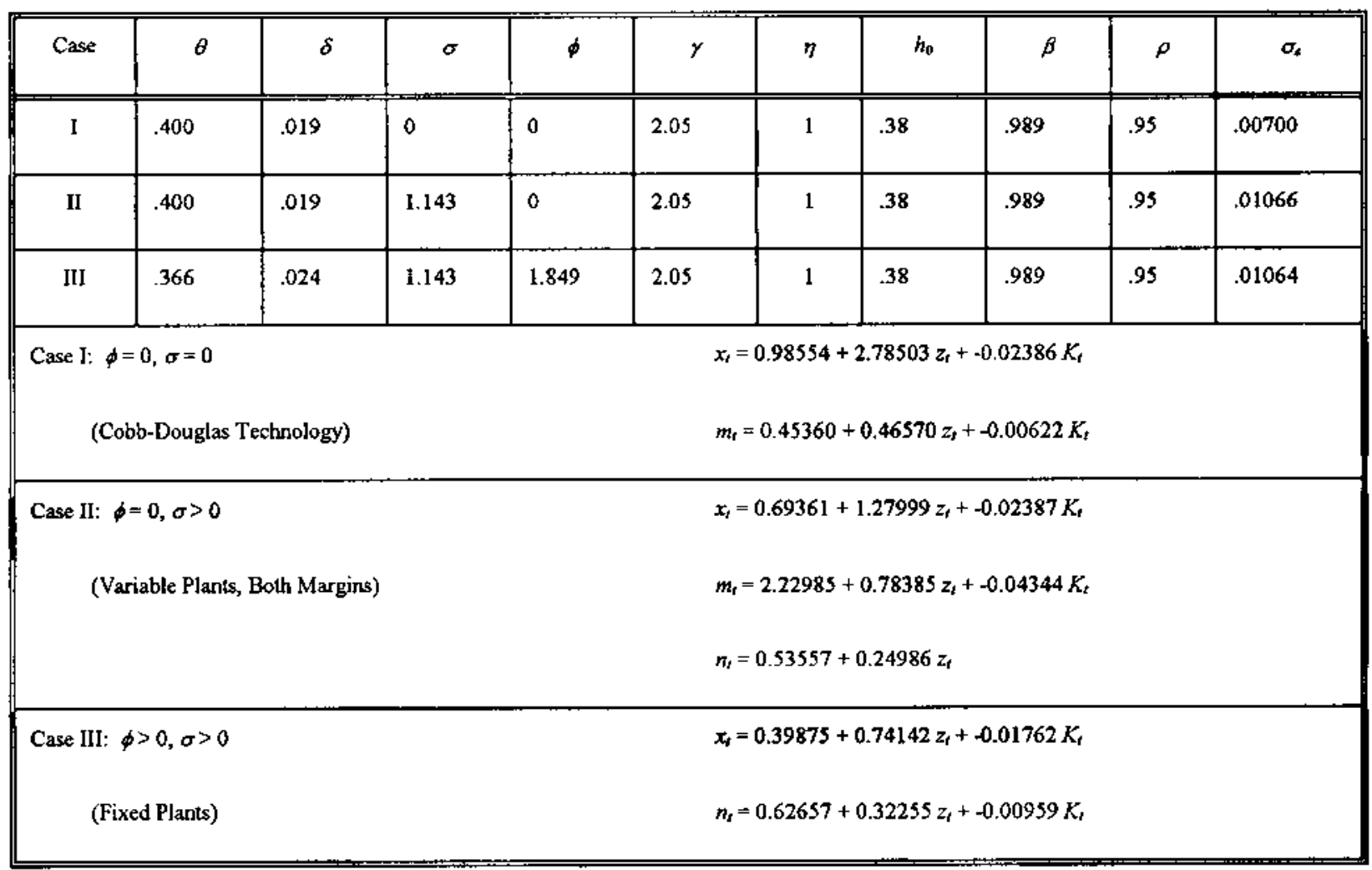

\section{Results and Conclusions}

In light of our calibration procedure and considering the form of the production functions in (18), one would expect that the numerical results for Cases I and II should be identical. This is because the production functions in the two cases are identical except that the Solow residuals are characterized by log first differences of $\mathrm{g}\left(z_{t}\right)$ in Case II rather than $\log$ first differences of $z_{t}$ (Case I). However, given our strategy for calibrating the $z_{t}$ process described in the previous section, we should expect the same results 
from simulating Case II as we obtain from Case I. This is because in Case II, $z_{t}$ is calibrated so that $\mathrm{g}\left(z_{t}\right)$ has the same statistical properties as $z_{t}$ has in Case $I$.

The production function for the fixed plants economy (Case III) is quite different from the other two. In the previous cases, the Solow residuals are functions of the exogenous state $z$ only. In Case III, Solow residuals calculated according to equation (19) will be complicated functions of both $z$ and the labor input. Hence, there is no reason to expect that results from simulating an economy based on this production function will look anything like results obtained from the other two models.

In Table 2 we present statistics summarizing the cyclical properties of each of our three economies. We also include statistics describing actual U.S. time series. The economy of Case I, in which all capital is employed in each period, displays cyclical properties that are in many ways quite similar to those of the actual economy: investment is over three times more variable (in percentage terms) than output, consumption is less than half as variable, and hours are less variable than output but almost twice as volatile as productivity." Consumption and productivity, however, fluctuate significantly less in the Case I economy than in the actual data.

As expected, we find that by adding the utilization margin (Case II), the cyclical properties of the economy are not affected. The only difference between Case I and Case II is that in the former, all of the fluctuation in hours worked is attributable to fluctuation in $m_{t}$. In the latter case, fluctuation in hours is attributable to movements in both $m_{t}$ and $n_{t}$. Hence, our preliminary finding is that variability in capital utilization along the extensive margin can be safely abstracted from in the real business cycle context.

The cyclical properties of the third economy, in which the utilization margin is the only way output can be varied in the short run, do differ from the other two. In particular, the fluctuations in output, investment and hours are all smaller than in the previous cases. In addition, consumption and productivity

\footnotetext{
11 Although the model is the same, the results differ slightly from those presented in Hansen (1985) since different parameter valucs are used.
} 
fluctuate more relative to output. In general, the cyclical properties of this economy are not as similar to those observed in the actual economy as those of Cases I and II. These results would tend to reduce somewhat our estimate of the importance of technology shocks for aggregate fluctuations.

There is, however, one aspect of observed fluctuations exhibited by the fixed plants economy that is not exhibited by the previous two cases: fluctuation in factor shares. As can be seen from equation (19), the economies with variable plants display constant factor shares; capital and labor shares are $\theta$ and (1- $\theta$ ), respectively. However, in the fixed plants case, factor shares are no longer constant. In particular, equations (8) and (14) can be used to obtain the following expression for labor's share: ${ }^{12}$

$$
\frac{w_{t} n_{t} m_{t} h_{0} \eta}{Y_{t}}=\frac{z_{t}+\sigma\left(1-2 n_{t}\right)}{z_{t}+\sigma\left(1-n_{t}\right)}
$$

As shown in Table 2, labor's share fluctuates about 30 percent as much as output in the U.S. economy and is negatively correlated with output. In Case III, labor's share fluctuates only about 8 percent as much as output and its correlation with output is too large in absolute value. An additional feature of U.S. time series not shown in Table 2 is that there is a phase shift with respect to labor's share and the cycle. Labor's share tends to bottom out about two quarters before output peaks. This phase shift is not displayed by our artificial economy.

Our objective in this paper was to determine whether incorporating varying capital utilization into the real busincss cycle framework changes our views about the importance of technology shocks for aggregate fluctuations. In so far as the Case II economy is a good abstraction, we must conclude that this feature does not change our conclusions at all. However, the assumptions underlying this economy are extreme; here, the number of plants can vary freely in response to realizations of the technology shock, $z$. Reflecting on the actual economy, it seems unreasonable to assume that the number of plants can be varied

\footnotetext{
12 Actually, this expression is valid for Case II as well. However, in that case it tums out that the expression is equal to a constant, $1-\theta$.
} 
so easily from quarter to quarter. Clearly there is sluggishness in actual economies that is being abstracted from in the Case II economy. Case III, however, is also extreme; the number of plants can not vary at all in response to $z$. This may not be such an unreasonable feature when focusing on economic activity at business cycle frequencies. In any event, the results for this case lead us to conclude that technology shocks are somewhat less important than one would conclude from studying a basic real business cycle model. However, we find that technology shocks are only slightly less important than what Kydland and Prescott (1991) conclude in their study of an economy with both employment and hours variation. Still, a better abstraction is probably one somewhere between Case II and III and we would need to study such an economy to obtain strong conclusions about the importance of variable capacity utilization. However, our tentative conclusion given the findings reported in this paper is that this feature seems to matter surprisingly little for business cycles. 


\section{References}

Bils, M., Cho, J-0.: Cyclical factor utilization. Manuscript, University of Rochester (1993).

Bresnahan, T. F., Ramey, V. A.: Output fluctuations at the plant level. NBER Working Paper No. 4105 (1992).

Cooley, T. F., Prescott, E. C.: Economic growth and business cycles. In Frontiers of Business Cycle Research. Princeton: Princeton University Press, forthcoming.

Greenwood, J., Hercowitz, Z., Huffman, G. W.: Investment, capacity utilization, and the real business cycle. American Economic Review 78, $402-417$ (1988).

Greenwood, J., Hercowitz, Z., Krusell, P.: Macroeconomic implications of investment-specific technological change. Manuscript, University of Rochester (1992).

Hansen, G. D.: Indivisible labor and the business cycle. Journal of Monetary Economics 16, 309-327 (1985).

Hansen, G. D., Prescott, E. C.: Recursive methods for computing equilibria of business cycle models. In Frontiers of Business Cycle Research. Princeton: Princeton University Press, forthcoming.

Hansen, G. D., Sargent, T. J.: Straight time and overtime in equilibrium. Journal of Monetary Economics $21,281-308(1988)$.

Kydland, F. E., Prescott, E. C.: Hours and employment variation in business cycle theory. Economic Theory 1, 63-81 (1991).

Raddock, R. D.: Recent developments in industrial capacity and utilization. Federal Reserve Bulletin 76, $411-435(1990)$.

Rogerson, R.: Indivisible labor, lottcrics and equilibrium. Journal of Monetary Economics 21, 3-16 (1988). 
Table 2 - Cyclical Properties of Actual and Artificial Economies

\begin{tabular}{|c|c|c|c|c|c|c|c|c|}
\hline \multirow[t]{2}{*}{ Series } & \multicolumn{4}{|c|}{ Percent Standard Deviation } & \multicolumn{4}{|c|}{ Correlation with Output } \\
\hline & Data & $\begin{array}{c}\text { Case } \\
\text { I }\end{array}$ & $\begin{array}{c}\text { Case } \\
\text { II }\end{array}$ & $\begin{array}{c}\text { Case } \\
\text { III }\end{array}$ & Data & $\begin{array}{c}\text { Case } \\
\text { I }\end{array}$ & $\begin{array}{c}\text { Case } \\
\text { II }\end{array}$ & $\begin{array}{c}\text { Case } \\
\text { III }\end{array}$ \\
\hline Output & 1.73 & 1.70 & 1.69 & 1.38 & 1.00 & 1.00 & 1.00 & 1.00 \\
\hline Consumption & 0.86 & 0.42 & 0.43 & 0.45 & 0.77 & 0.84 & 0.83 & 0.89 \\
\hline Investment & 5.34 & 5.86 & 5.83 & 4.41 & 0.90 & 0.99 & 0.99 & 0.99 \\
\hline Capital Stock & & 0.38 & 0.38 & 0.38 & & 0.03 & 0.03 & 0.07 \\
\hline Hours & 1.50 & 1.35 & 1.34 & 0.82 & 0.86 & 0.99 & 0.99 & 0.99 \\
\hline Productivity $(Y / H)$ & 0.88 & 0.42 & 0.42 & 0.58 & 0.50 & 0.86 & 0.86 & 0.98 \\
\hline Labor's Share & 0.54 & & & 0.11 & -0.32 & & & -0.91 \\
\hline Measure of Plants $(m)$ & & 1.35 & 0.72 & & & 0.99 & 0.96 & \\
\hline Fraction of Plants Operating ( $n$ ) & & & 0.63 & 0.82 & & & 1.00 & 0.99 \\
\hline
\end{tabular}

Data: Quarterly U.S. time series from 1954:1 - 1991:3. Output is Gross National Product; Consumption is purchases of nondurables and services; and Investment is fixed investment. All are measured in 1982 dollars. Hours is total weekly hours worked in all industries based on the Current Population Survey (LHOURS in Citibase) and Productivity is Output divided by Hours.

Case I: Technology is Cobb-Douglas ( $\phi=0$ and $\sigma=0$ ).

Case II: Variable number of plants with both margins operating ( $\phi=0$ and $\sigma>0)$.

Case III: Fixed number of plants $(\phi>0$ and $\sigma>0)$.

All series have been logged (except labor's share) and filtered using the Hodrick-Prescott filter. Standard deviations are expressed as percents. The statistics describing the model economies are means of statistics computed for 100 simulations of 151 periods each. 